REVISTA DE DERECHO UNED, núm. 2, 2007

\title{
BREVES APUNTES SOBRE LA RENUNCIA AL DERECHO A LA PENSIÓN COMPENSATORIA
}

\author{
SANDARA DIAZ MASEDA
}

Resumen: En líneas generales, los mayores de edad son capaces para todos los actos de la vida civil, por esta razón, los cónyuges pueden celebrar entre sí toda clase de actos y contratos, establecer los pactos, cláusulas y condiciones que tengan por conveniente, con los únicos límites impuestos por las leyes, la moral y el orden público. Siguiendo esta pauta, el mero consentimiento obliga al cumplimiento de lo convenido, pero, ¿pueden los cónyuges pactar todo lo que tengan por conveniente? ¿Pueden pactar cuando sus intereses colisionan con los de sus hijos?

Abstract: In general, the grown-ups are capable for all the acts of the civil life, for this reason, the spouses can celebrate between them all kinds of acts and contracts, to establish the agreements, clauses and conditions to be suitable, with the only limits imposed by the laws, the morality and the public order. Following this guideline, the simple consent forces to fulfilment of the been convenient, but, can spouses agree on everything that they have for suitable? Can they agree on when their interests crash with their children?

Palabras clave: 1.-Capitulaciones matrimoniales: contrato sobre bienes con ocasión del matrimonio otorgado antes de celebrarlo o durante el mismo y por el cual se estipulan las condiciones de la sociedad conyugal relativa a los bienes presentes y futuros.

2.-Convenio regulador: documento en el que ambos cónyuges pactan de mutuo acuerdo las relaciones económicas, así como las relativas a los hijos en los casos de separación o divorcio

3.-Desequilibrio económico: disminución patrimonial que, como consecuencia de las circunstancias que guiaron la vida matrimonial, 
experimentan las condiciones de vida materiales de uno de los cónyuges al momento de cesar la convivencia conyugal, situándole en una posición desfavorable respecto a la del otro y a la que disfrutaba durante el periodo de normalidad del matrimonio.

4.-Pensión compensatoria: cantidad periódica que un cónyuge debe satisfacer a otro tras la separación o el divorcio para compensar el desequilibrio padecido por un cónyuge (el acreedor) en relación con el otro cónyuge (el deudor), como consecuencia directa de dicha separación o divorcio, que implique un empeoramiento en relación con su anterior situación en el matrimonio.

5.-Renuncia: Dimisión o dejación voluntaria de algo que se posee, o del derecho a ello.

\section{INTRODUCCION}

La pensión de desequilibrio se fija por el juez cuando las circunstancias concurrentes en el momento de la crisis acreditan la existencia de un empeoramiento en las condiciones de vida de uno de los cónyuges que debe ser corregido según la concepción que el Legislador tiene de la forma más justa de regular la crisis matrimonial. Si se tiene derecho a ella es porque el juez, valorando las circunstancias que enuncia el propio artículo 97 del código civil, entiende que uno de los esposos queda en situación más desfavorable que el otro y que ésta debe ser corregida. La protección del cónyuge más desfavorecido, su inseguridad personal, la desigualdad en la que queda y la atención de sus necesidades para desarrollar su propia dignidad, integran la ratio de la norma.

Expuesto lo anterior, ¿pueden los futuros contrayentes pactar en capitulaciones matrimoniales, la exclusión del art. 97 del Código Civil para el supuesto de que se produzca en su día la crisis matrimonial?; ¿es válido el acuerdo autorizado por Notario al contraer matrimonio, en el que estipulen que no les será de aplicación el art. 97? Argumentaciones tales como el carácter dispositivo de dicha norma; el reconocido juego de la autonomía de la voluntad en la regulación de la crisis; la existencia de un consentimiento libre y consciente, constatado por fedatario público; el no poder ir contra los actos propios; o la eficacia vinculante del negocio jurídico, son, entre otras, las razones que persuaden de la razonabilidad de la elección afirmativa.

Sin embargo, no debe perderse de vista que la pensión que constituye el art. 97 tiene como objeto compensar la disparidad econó- 
mica que la ruptura del matrimonio crea en las condiciones de vida respectivas de los esposos, disparidad que se cuantifica atendiendo a las necesidades de un cónyuge y a los recursos del otro, teniendo en cuenta esas situaciones en el preciso momento de la crisis y la evolución en un futuro previsible. Puede observarse, pues, que esta definición es suficiente para dar al traste con la presunta validez del acuerdo de exclusión en todos los casos, ya que con él se pretende dejar sin efectos una norma cuyo imperativo hipotético condicionado es la comparación de las situaciones respectivas de los cónyuges en el momento de la crisis, comparación que es imposible de realizar si la crisis aun no se ha producido. La exclusión trae pues consigo que se esté en presencia de una renuncia futura a los beneficios de la ley sin que exista para ello justificación o compensación razonable. Y ello es así, porque si se pacta la exclusión a la pensión y posteriormente el cónyuge que la interesa no tiene derecho a la misma, se habrá previsto una situación futurible coincidente con la posterior realidad; pero si valoradas por el Juez las circunstancias concurrentes en el momento de la separación o el divorcio, correspondiere su concesión, $\mathrm{y}$, no obstante, hubiere sido excluida antes de contraer matrimonio, el perjuicio injustificado es evidente. Por ello, será necesario poner de manifiesto las circunstancias concurrentes en cada supuesto para poder valorar la eficacia de los mentados pactos.

Cuestión distinta se produce cuando los cónyuges una vez producida la ruptura conyugal pactan la renuncia a la pensión compensatoria, ya que, en estos supuestos, la renuncia será admisible en todo caso, siempre, claro esta, que el convenio regulador en el que se pacte la renuncia sea aprobado por el juez.

\section{POSIBILIDAD DE RENUNCIA}

Dentro de la disponibilidad de los cónyuges de la pensión compensatoria ha sido objeto de especial y concreto estudio la renuncia a este derecho. Exigiéndose en primer lugar y, en todo caso, que la renuncia sea personal, clara ${ }^{1}$, terminante, inequívoca, sin condicionante alguno y con expresión indiscutible de la voluntad determinante de la misma.

1 Tal y como se exige en sentencias como la AP, Sección $2 .^{a}$, Las Palmas 23 de noviembre de 1998 (Pte.: Parejo Pablos) y AP Barcelona 11 de octubre de 1989 (RGD 1990, p. 2676). 
Es eficaz, en principio, la contenida en convenio regulador homologado, como también lo es el pacto en dicho convenio de no pagar la pensión. Se trata de un pacto libre y entre iguales, que se hace depender en última instancia del arbitrio de los conyuges, quienes pueden renunciar a los beneficios que la ley les otorga sin que tal renuncia parezca injusta, ya que al que consiente no se le hace daño, volenti non fit iniuria; la exclusión al beneficio legal es, pues, una manifestación de la libertad y de la igualdad, por quedar ambos idénticamente desprovistos de la pensión compensatoria. Con lo que se pone el fundamento del valor de la justicia, a falta de otros criterios no aprensibles, en la voluntad de las partes, en las elecciones preferenciales realizadas por la voluntad, es decir, en ser libres para regular sus intereses conforme a lo que más les convenga.

De todas formas, debe plantearse aquí una cuestión que se deduce del texto del artículo $90 \mathrm{CC}$. Este precepto impone la obligación de aprobar los pactos contenidos en los convenios reguladores de la nulidad, separación y divorcio, con dos únicas excepciones: la primera es si los pactos son dañinos para los hijos, y la segunda que sean gravemente perjudiciales para los cónyuges.

A la luz de este precepto y de una aplicación conforme con la literalidad de su texto, nos encontraríamos con que, en ocasiones, podría el juez rechazar la renuncia a una pensión compensatoria, que no estuviera marcada por la inexistencia de desequilibrio -que no sería una verdadera renuncia, al no concurrir la exigencia básica para el nacimiento del derecho-. En algún supuesto, incluso, podrá desaprobarse por considerar la existencia de un perjuicio indirecto para los hijos, si la renuncia la realiza el progenitor con el que vayan a convivir, que dispondría de menores medios para compartir con ellos. Pero, desde luego, en los restantes casos, de aplicar esta teoría debería realizarse, en todo caso, porque la renuncia a un derecho pecuniario sería siempre "gravemente perjudicial para uno de los cónyuges: el renunciante».

En todo caso, en las resoluciones judiciales que han contemplado la validez y eficacia de la renuncia se pone de manifiesto una gran cautela, subrayando que la interpretación ha de ser restringida.

\section{MOMENTO DE LA RENUNCIA}

Existe una línea jurisprudencial amplia que considera nula la renuncia hecha antes del matrimonio, por estimar, en aplicación de la doctrina sentada, entre otras, por la sentencia del Tribunal Supremo 
de 18 de noviembre de 1957 (RJ1957/9876), que sólo cabe tal renuncia respecto de los derechos que tienen por objeto algún concreto elemento de los que se encuentren en el patrimonio jurídico del renunciante, por haberlos adquirido ya éste en el momento de la renuncia. Asimismo, aplican estas resoluciones la doctrina contenida en las sentencias del Tribunal Supremo de 18 de marzo de 1982 (RJ 1982, 1385) y 21 de abril de 1997 (RJ 1997, 3434) sobre la imposibilidad de renunciar a un derecho que todavía no ha nacido.

Ello nos lleva al examen de una de las cuestiones de mayor actualidad en el Derecho de Familia como es el valor y eficacia de los pactos prenupciales, así como la extensión objetiva de los mismos. La proliferación de los fracasos conyugales viene llevando en todo Occidente a la búsqueda de mecanismos cautelares para evitar o paliar los efectos que se consideran nocivos o para asegurar de alguna forma los efectos o consecuencias de la ruptura.

\section{1. ${ }^{\circ}$ CAPACIDAD}

En líneas generales, los cónyuges, a tenor del art. $1.323 \mathrm{CC}$, pueden celebrar entre sí toda clase de actos y contratos. Los mayores de edad son capaces para todos los actos de la vida civil (art. $322 \mathrm{CC}$ ). El menor no emancipado que con arreglo a la Ley pueda casarse podrá otorgar capitulaciones, pero necesitará el concurso y consentimiento de sus padres o tutor, salvo que se limite a pactar el régimen de separación o el de participación (Art. 1.329 CC). Por lo tanto, estos menores no emancipados son los mayores de catorce años y menores de dieciocho a los que a tenor del art. $48 \mathrm{CC}$, el juez de primera instancia les haya concedido dispensa al efecto, con justa causa y a instancia de parte. El incapacitado judicialmente sólo podrá otorgar capitulaciones matrimoniales con la asistencia de sus padres, tutores o curadores (art. $1.330 \mathrm{CC}$ ). Cuando se trata de capitulaciones posteriores al matrimonio, aunque un consorte no haya alcanzado la mayoría de edad, estará capacitado para otorgarlas por estar emancipado por el matrimonio (art. 314. 2. ${ }^{\circ} \mathrm{CC}$ ). Ahora bien, si entre los pactos hay alguno que entrañare tomar dinero a préstamo, enajenación o gravamen de inmuebles, establecimientos mercantiles o industriales u objetos de extraordinario valor, el emancipado soltero precisa del consentimiento de sus padres y a falta de ellos, el de su curador o tutor ${ }^{2}$ art. $323 \mathrm{CC}$ ). Pero para estos actos - excepto el tomar

${ }^{2}$ Hasta la LO 1/1996 de 15 de enero de Protección del Menor, este artículo citaba al tutor, sustituido por dicha ley por el curador, pero en realidad debía considerar la doble posibilidad de que tenga tutor o curador. 
dinero a préstamo- si fuera casado y si se tratara de bienes comunes, si el otro cónyuge es mayor de edad basta el consentimiento de ambos, pero si éste es también menor, se necesitará el de sus padres o curador ${ }^{3}$.

A estas consideraciones ha de unirse que el art. $1.331 \mathrm{CC}$ establece que para que sea válida la modificación de las capitulaciones matrimoniales deberá realizarse con la asistencia y concurso de las personas que en éstas intervinieron como otorgantes si vivieren y la modificación afectare a derechos concedidos por tales personas.

\subsection{LOS CONVENIOS}

Con carácter general hay que recordar el principio de autonomía de la voluntad y libertad de pactar, de forma que el art. $1.255 \mathrm{CC}$ establece que los contratantes pueden establecer los pactos, cláusulas y condiciones que tengan por conveniente. Los límites que señala este mismo precepto a la libertad citada están impuestos por las leyes, la moral y el orden público. La validez y eficacia de los contratos no puede dejarse al arbitrio de uno de los contratantes (art. $1256 \mathrm{CC}$ ), los contratos se perfeccionan por el mero consentimiento y desde ese momento obligan al cumplimiento de lo convenido y a todas las consecuencias que sean conforme a la buena fe, al uso y a la ley (art. $1258 \mathrm{CC})^{4}$.

Para que exista contrato han de concurrir consentimiento libre -no prestado por error, violencia, intimidación o dolo-, objetoque no puede estar fuera de la disponibilidad de los hombres- y causa - que incluye la mera liberalidad en los de pura beneficencia (arts. 1261 y sigtes. CC).

Específicamente entre cónyuges ${ }^{5}$, como ya hemos señalado, el art. 1.323 CC autoriza a los esposos a celebrar entre sí toda clase de actos y contratos, naturalmente con los límites establecidos ante-

${ }^{3}$ Id.

4 La SAT Bilbao 9. 7. 82 reconoció la validez de los pactos de separación de hecho.

5 Sentencia Audiencia Provincial Barcelona de 26 de octubre de 2004, Sección 18. ${ }^{a}$, AC 141/2004: «En el presente caso las partes pactaron en el convenio mencionado que el esposo abonaría a la apelante por dicho concepto la cantidad de 15.000 Pts. durante tres años. Pues bien, habiendo transcurrido tal límite temporal, habiéndosele otorgado una pensión en la sentencia por idéntica cuantía y límite temporal, es obvio que de acuerdo con lo expuesto, en ningún caso procede aumentarla en los términos pretendidos, por lo que debe desestimarse el motivo que se examina". 
riormente. Al propio tiempo el art. $1.328 \mathrm{CC}$ establece que «será nula cualquier estipulación contraria a las leyes o a las buenas costumbres o limitativa de la igualdad de derechos que corresponda a cada cónyuge».

\section{3. ${ }^{\circ}$ LAS CAPITULACIONES MATRIMONIALES}

Según el art. $1.325 \mathrm{CC}$ el contenido de las capitulaciones matrimoniales está delimitado por la estipulación, modificación o sustitución del régimen económico del matrimonio o cualesquiera otras disposiciones por razón del mismo. La conjunción disyuntiva "o» determina que pueden ser capitulaciones las que versen sobre el régimen económico, sobre otras disposiciones por razón de dicho matrimonio o sobre ambas cuestiones. Por lo tanto, un convenio sobre cuestiones ajenas al régimen económico conyugal puede constituir capitulaciones, pero puede no serlo. Mientras que si se estipula, modifica o sustituye el mencionado régimen económico ha de ser por capitulaciones, con las solemnidades que exige la ley para las mismas, ya que el art. 1.315 C.C. determina que el régimen económico del matrimonio será el que los cónyuges estipulen en capitulaciones matrimoniales, sin otras limitaciones que las establecidas en este Código.

Para su validez, las capitulaciones matrimoniales, que podrán otorgarse antes o después de celebrado el matrimonio, habrán de constar en escritura pública (arts. 1.326 y $1.327 \mathrm{CC}$ ). Esta forma, que en las capitulaciones es requisito esencial sin el cual son absolutamente nulas, no se exige en cualquier otro pacto relacionado con el matrimonio o su ruptura. También concretamente referido a la ley aplicable, el art. 9.3 CC declara la validez de los pactos o capitulaciones por los que se estipule, modifique o sustituya el régimen económico del matrimonio cuando sean conformes, bien a la ley que rija los efectos del matrimonio, bien a la ley de la nacionalidad o de la residencia habitual de cualquiera de las partes al tiempo del otorgamiento.

En cuanto a su contenido hay que considerar que puede referirse, fundamentalmente a la determinación del régimen económico matrimonial que es el primer contenido de las capitulaciones otorgadas antes o después del matrimonio. El art. $1.315 \mathrm{CC}$ concede absoluta prioridad a la voluntad de las partes para elegir el régimen conyugal. Sólo en defecto de determinación por las partes en capitulaciones, el 
régimen económico conyugal será el subsidiario, que variará de acuerdo con la legislación aplicable al caso ${ }^{6}$.

Pero la complejidad del sistema jurídico español, superpone a la nacionalidad una figura que nos es propia: la vecindad civil. Se trata de una especie de nacionalidad, que no de domicilio o residencia, entre otras razones porque la forma primera de adquirirla está ligada al ius sanguinis y es precisamente esta condición la que determina la sujeción al derecho civil común o al especial o foral (art. 14 CC). La dificultad de conocer la vecindad civil no sólo proviene de la proliferación de parejas de progenitores que no tienen la misma vecindad civil de origen (por nacimiento), sino de la forma en que la pueden adquirir y perder por residencia.

Hay que partir de la migración numerosa dentro de la propia España y de nacionales españoles y hay que tener muy en cuenta que existe una forma de cambiar de vecindad generadora de enorme inseguridad jurídica, por diez años de residencia en otro territorio, sin expresar una voluntad contraria a ello de manera formal ante el Registro Civil, la persona altera su vecindad. Lo que ocurre es que eso no lo sabe nadie. Es cierto que la ignorancia de la ley no exime de su cumplimiento $\mathrm{y}$, en consecuencia, el emigrante a otra región que permanece diez años continuados con residencia en ella adquiere esa nueva vecindad con hondas repercusiones en cuanto al régimen económico del matrimonio que contraiga después de tal cambio.

Por otra parte, la propia norma de conflicto -internacional y nacional- incrementa la inseguridad enormemente, puesto que se refiere, cuando nada se pacta de modo expreso en cuanto a cual de las leyes de las partes es la aplicable, a la ley del lugar del primer domicilio después del matrimonio, que puede demorarse en su determinación o ser de incierta constancia.

Como decíamos, la determinación de ley aplicable es de gran importancia en el orden internacional, con el gran número de matrimonios internacionales y tantos sistemas jurídicos conyugales tan diferentes, según pertenezcan los países al área legal heredera del Código Napoleónico o la esfera del common law. Es cierto que la existencia de un punto de partida - la nacionalidad- es más constatable que la vecindad civil, pero la divergencia entre las normas de derecho internacional privado de las distintas naciones produce, en ocasiones,

${ }^{6}$ Art. 1.316 CC; arts. 23 y 36 de la Compilación Aragonesa; art. 10 Código de Familia Catalán; Ley 82 de la Compilación Navarra; arts. 93 y 94 del Derecho civil foral del País Vasco; y art. 3. 1 de la Compilación Balear. 
el efecto de una doble o triple nacionalidad no reconocida o regulada por ninguno de los países afectados que determinan quienes son sus nacionales sin atender a las leyes de los demás Estados. Y naturalmente a los problemas derivados de la nacionalidad discrepante entre los esposos se añade la todavía más compleja de la diversidad de vecindades civiles, aunque exista la posibilidad (arts. 16 y $9 \mathrm{CC}$ ), de convenir la aplicable cuando carezcan los conyuges de ley común.

Las consecuencias de lo expuesto son extraordinarias, en el orden internacional, la inexistencia de todo régimen económico conyugal, como ocurre en los países sajones, o la concurrencia de separaciones de bienes o regímenes de comunidad y aún las normas a que los mismos están sujetas, son trascendentales.

Por lo que se refiere a los pactos anteriores en el matrimonio, debemos partir de las premisas antes indicadas de la libertad de pactar que alcanza a los cónyuges o futuros cónyuges. Pero, en primer término, habría que preguntarse ¿es posible legalmente alcanzar pactos relativos a la ruptura del matrimonio?

Nada hay que se oponga, en términos generales, a la libertad de pactar, ya sea en capitulaciones o en cualquier otro documento ${ }^{7}$,

${ }^{7}$ En relación con este tema, la STS, Sección $1 .^{\text {a }}$, de 22 de abril de 1997, Sentencia n. 325 (RJ 1997/3251) Pte. O.Callaghan Muñoz, se ocupa de ello señalando lo siguiente: «la cuestión jurídica esencial que se plantea es la naturaleza jurídica del convenio regulador, en las situaciones de crisis matrimonial, contemplado y previsto su contenido mínimo en el artículo 90 del Código Civil, que no ha obtenido la aprobación judicial. En principio, debe ser considerado como un negocio jurídico de derecho de familia, expresión del principio de autonomía privada que, como tal convenio regulador, requiere la aprobación judicial, como "conditio iuris", determinante de su eficacia jurídica".

La Sentencia de 25 junio 1987 (RJ 19874553) declara expresamente que "se atribuye trascendencia normativa a los pactos de regulación de las relaciones económicas entre los cónyuges, para los tiempos posteriores a la separación matrimonial'; la de 26 enero 1993 (RJ 1993ไ365) 'añade que la aprobación judicial del convenio regulador no despoja a éste del carácter de negocio jurídico que tiene como manifestación del modo de autorregulación de sus intereses querido por las partes»

En una línea semejante la STS, Sección 1. a, de 27 de enero de 1998, n. ${ }^{\circ}$ 31/1998 (RJ 1998/110) Pte: Almagro Nosete que comienza por centrar el tema discutido en que "del examen de los fundamentos jurídicos de la sentencia recurrida se desprende que la cuestión jurídica que se plantea y resuelve por la Sala de instancia no es la referente a la validez de unas capitulaciones matrimoniales que hubieran establecido el régimen de separación de bienes, por medio de documento privado, constante matrimonio, sino el de la eficacia jurídica de un convenio regulador de la separación de los cónyuges, formalizado por documento privado en el que se pacta, entre otros extremos el régimen económico de separación de bienes, antecedente a la posterior tramitación de la separación judicial. Esto es, se plantea, supuesto el mencionado pacto, si la adqui- 
cuestiones relacionadas con la separación o el divorcio del matrimonio o, en casos de parejas de hecho, de la quiebra de su convivencia. El libre ejercicio de la facultad de autorregulación de las relaciones privadas está reconocida por la jurisprudencia ${ }^{8}$, naturalmente condicionada a la concurrencia de los requisitos estructurales establecidos por la ley con carácter general (art. 1261 CC) ${ }^{9}$.

Como consecuencia de ello, hay que concluir que los pactos entre cónyuges reguladores de su ruptura, que no han sido sometidos a la aprobación judicial, son un negocio jurídico de derecho de familia y que la validez de lo convenido es evidente, aunque pueda resultar ineficaz alguna de sus estipulaciones por su contenido, pero que, a prio$r i$, son válidos y eficaces.

Respecto de los pactos preventivos de la separación o el divorcio dentro de los límites del artículo $1.255 \mathrm{CC}$, los cónyuges pueden celebrar válidamente convenios en previsión de las situaciones de crisis matrimonial sobre cuestiones disponibles. Con carácter más específico el art. 15.1 del Código de Familia de Cataluña ${ }^{10}$ determina la libre regulación de las relaciones familiares, con posibilidad de incluir en los capítulos matrimoniales las estipulaciones y pactos lícitos en previsión de una ruptura matrimonial, abriendo así la puerta al reconocimiento legal de estas estipulaciones preventivas de futuro que ya comienzan a tener algún reflejo en la sociedad ${ }^{11}$.

sición del bien, ocurrida durante el período de separación de hecho, después de la suscripción del expresado documento privado y antes de iniciarse el proceso de separación matrimonial, determina, sin más, el carácter ganancial del bien o permite considerarlo como privativo del cónyuge que lo adquirió».

Y más adelante: «la cuestión jurídica relativa al valor del convenio privado regulador de la separación no aprobado judicialmente o pendiente de aprobación judicial» «la Sentencia de esta Sala de 22 abril 1997 (RJ 1997 3251) establece que 'no hay obstáculo a su validez como negocio jurídico en el que concurrió el consentimiento, el objeto y la causa, y no hay ningún motivo de invalidez. No lo hay tampoco para su eficacia, pues si carece de aprobación judicial, ello le ha impedido ser incorporado al proceso y producir eficacia procesal, pero no la pierde como negocio jurídico'.

8 SSTS 26-1-1993 (EDJ 1993/509), 7-3-1995 (EDJ 1995/586), 22-4-97 (EDJ 1997/2156) 19-12-1997 (EDJ 1997/8995) y 27-1-1998 (EDJ 1998/16), 21-12-1998 (EDJ 1998/30785) y RDGRN 31-3-1995, 10-11-1995, 1-9-1998.

9 Incluso las SSTS 28 feb.1969 y 17 jun. 1972, anteriores a 1981 reconocieron la validez de un pacto en separación de hecho relativo a la prestación de asistencia económica.

${ }_{10}$ Ley 9/1998, de 15 de julio, del Código de Familia. BOE 198/1998, de 19 agosto 1998, Ref. Boletín: 98/20137.

11 DGRN 19-6-2003 EDD 2003/112605. Resuelve un supuesto en el que se intentaban inscribir unas capitulaciones matrimoniales que tenian como contenido exclusivo unas estipulaciones para el supuesto de que en un futuro se produjera una separación judicial y/o un divorcio, considerando la DGRN que estos pactos futuros en 
Sea en capitulaciones matrimoniales como fuera de ellas, los futuros consortes o los cónyuges después de su matrimonio pueden establecer pactos relativos a su ruptura. La cuestión objeto de debate es la determinación de cuales de estos pactos son válidos y cuales no, por superar los límites de la ley, de la moral o el orden público, rebasando las fronteras de lo disponible.

Es cierto que el art. 751. 1. ${ }^{\circ}$ LEC establece que no surtirán efecto la renuncia, el allanamiento, ni la transacción en los procesos a que se refiere el título I del Libro IV, entre los que se encuentran los de separación y divorcio. Pero es igualmente verdadero que el apartado $3 .^{\circ}$ del mismo artículo determina que "no obstante lo dispuesto en los apartados anteriores, las pretensiones que se formulen en los procesos a que se refiere este Titulo y que tengan por objeto materias sobre las que las partes puedan disponer libremente, según la legislación civil aplicable, podrán ser objeto de renuncia, allanamiento, transacción o desistimiento, conforme a lo previsto en el Capítulo cuarto del Titulo primero del Libro primero de esta Ley».

Por otra parte, el art. $1.328 \mathrm{CC}$ establece que «será nula cualquier estipulación contraria a las leyes o a las buenas costumbres o limitativa de la igualdad de derechos que corresponda a cada cónyuge».

Concretándonos a la pensión compensatoria del art. 97 CC, hay que señalar que quizás sean éstas las cuestiones dentro del orden económico en que exista una mayor demanda de regulación preventiva de la ruptura. La legalidad o la eficacia de limitar su cuantía o renunciar a la percepción de esta pensión es la cuestión a contemplar.

Si esta delimitación cuántica o la renuncia o reconocimiento de la inexistencia del derecho a su percepción se incluyen en el convenio regulador de la separación o el divorcio, que se firma para regular la ruptura y ésta tiene lugar, el pacto es válido y eficaz. Como ya hemos dicho reiteradamente, el Tribunal Supremo, en Sentencia de 2 de diciembre de 1987 recaída en recurso de casación en interés de ley ${ }^{12}$, ha reconocido el carácter disponible de la pensión compensatoria y, por lo tanto, la validez y eficacia de su renuncia.

El problema más complejo es si la renuncia es válida cuando se produce en capitulaciones matrimoniales o en un pacto anterior al

\footnotetext{
previsión de una eventual ruptura matrimonial, sin perjuicio de su validez, quedan al margen de la publicidad registral.

Vid también el art. 3 de la Ley aragonesa de régimen matrimonial Ley 2/2003 de 12 de febrero de régimen económico matrimonial y viudedad de Aragón.

12 Pte.: Fernández-Cid de Temes
} 
matrimonio y preventivo de la ruptura, significativamente precedente a los problemas de la pareja. Aunque no abundan las resoluciones judiciales en esta materia, ha venido resultando emblemática, para quienes defienden la irrenunciabilidad preventiva de la pensión compensatoria, la sentencia de la SAP de Asturias de 12 de diciembre de 2000, SAP Asturias, Sección 5. a 12-12-2000, Pte. Muriel Fernández-Pacheco, M. ${ }^{a}$ Pilar, sent: 690/2000, Rec: $217 / 2000^{13}$.

13 En el caso contemplado en ella, la esposa, en escritura pública de liquidación de la sociedad de gananciales renunció, al igual que su esposo, a la pensión compensatoria. Diez años más tarde, la propia mujer pretende invalidar la renuncia alegando en el proceso de separación que el consentimiento no fue prestado libremente sino coaccionada por su esposo. No obstante la alegación de la parte, la Sala examina de oficio (Coincide en la posibilidad de apreciar de oficio si el acuerdo relativo a pensión compensatoria es gravemente lesivo la SAP Málaga, Sección 5.a . ; 30-4-04, Pte: Fernández Ballesta, sent 509/2004; Rec 658/2003; SP/SENT/58150) y dictamina la invalidez de dicha renuncia, partiendo de que se trata de una renuncia a un derecho futuro, hipotético e incierto, que nace en el momento de la separación y está sujeto a la condición de que la misma produzca desequilibrio económico en relación con la posición del otro, que implique un empeoramiento en relación con la situación que se mantenía en el matrimonio (Vid. LOPEZ MARCO, Pilar: Renuncia anticipada a la compensación por desequilibrio económico derivado de la separación o divorcio. Comentario a la sentencia 690/2000 de 12 de diciembre de la AP Asturias (S. 5.a)» Pendiente de publicación.) El problema, pues, que se plantea es la eficacia de los pactos que los cónyuges puedan celebrar relativos a una expectativa de derecho, derecho futuro o derecho condicional.

En cuanto a lo que puede ser objeto de renuncia la AP de Asturias afirma que conforme a la doctrina del Tribunal Supremo «la renuncia de derechos no puede referirse a otros que los reconocidos por la legislación vigente al tiempo de realizarse aquélla, pero no a los establecidos y regulados en la legislación posterior (SS 24 febrero y 30 marzo 1951, 18 diciembre 1952, 21 enero 1965)", lo que parece evidente.

Esta tesis en contra de la admisión de la renuncia preventiva de la pensión compensatoria parte de la premisa de que no cabe renunciar a un derecho que aún no ha nacido. Sobre el momento del nacimiento del derecho de pensión compensatoria, la SAP Baleares, Sección 4. ${ }^{a}$, de 16 de febrero de 1998 (Pte: Zaforteza Fortuny (EDJ 1998/5326) afirma que "...las resoluciones jurisdiccionales meramente declarativas se basan en la existencia de la relación jurídica con anterioridad al litigio, mientras que las constitutivas producen ellas mismas la creación, modificación o extinción de un derecho siendo indiscutible que la sentencia de divorcio tiene naturaleza constitutiva (artículo 89 del Código Civil), parece también obvio que el pronunciamiento incluido en la misma resolución en orden a estatuir una pensión compensatoria - como medida económica derivada del divorcio, a tenor de lo previsto en el artículo 97 del Código Civil-es también constitutivo, en cuanto da lugar al nacimiento de ese derecho pecuniario, pues mantener lo contrario conduciría al absurdo de que lo accesorio produciria sus efectos antes que lo principal de que dimana (En el mismo sentido, AP Córdoba, Sección 2. a, S 25-4-2002, Pte: Verdugo y Gomez de la Torre, Juan Ramón (EDJ 2002/24188) y AP Castellón. Sección 2. ${ }^{a}$ s 13-2-1999, Pte: Domínguez Domínguez, Carlos (EDJ 1999/13817). De acuerdo con esta tesis, sólo a partir de la decisión judicial que establece la pensión el cónyuge beneficiario puede ejercitar su derecho o proceder a su extinción mediante renuncia. Sin embargo, llevando esta posición a sus últimos extremos, no sería dis- 
No obstante, cuando la renuncia figura en el convenio regulador, aunque éste preceda al nacimiento del derecho a la pensión, que surge de la sentencia que establece la separación o el divorcio, el hecho de que se redacte y firme precisamente para surtir efectos en la ruptura del matrimonio, permite interpretar que los otorgantes reconocen la ausencia de desequilibrio ${ }^{14}$. Pero no sólo cabe esta interpretación. La renuncia puede obedecer a causas más nobles o motivos más generosos, que no podemos desconocer. Porque el reconocimiento de que no existen los fundamentos legales para la fijación de la pensión compensatoria, en principio, no constituye una renuncia, porque no existe el derecho. Y de lo que estamos hablando aquí es de la verdadera renuncia, que parte de la concurrencia de los requisitos de todo orden para que nazca el derecho y el rechazo a su percepción. Bien es verdad que, en alguna ocasión, el reconocimiento de que se carece del derecho encubre en realidad una renuncia, porque el renunciante tendría ese derecho y sólo se trata de una forma de encubrir el rechazo a través del reconocimiento de su inexistencia.

Cuando se habla de la eficacia de la renuncia hay que referirse a aquella que tiene como objeto un derecho existente o que puede existir y en la que los móviles pueden ser diferentes: morales, sociales,

ponible la pensión, en contra de la doctrina del Tribunal Supremo, en los convenios reguladores de la separación o el divorcio, porque los mismos, por definición, siempre preceden a la sentencia.

La SAP Barcelona, Sección 12. a , 17-3-2000 (Ref: SP/SENT.26045), con acierto ha determinado que «el pacto por el que se renunció a la pensión compensatoria es plenamente válido y eficaz, al tratarse de una materia de derecho dispositivo y ser de aplicación a la misma lo establecido en el artículo 1254 del Código Civil, sin que tenga ninguna trascendencia al respecto que después de la firma del contrato no ratificase la solicitud de separación consensuada promovida por los trámites del mutuo acuerdo, ya que en lo que se refiere a la pensión compensatoria, el artículo 97 del Código Civil establece como primero de los criterios a aplicar, el de los acuerdos alcanzados por los cónyuges».

Aunque con alguna reiteración las dos Salas de Familia de la Audiencia Provincial de Barcelona profesan opiniones distintas, en esta materia, la otra Sección, la 18. ${ }^{a}$ coincide con la anterior en su sentencia de 31 de julio de 2002 (Ref: SP/ Sent. 40492) "El convenio no homologado judicialmente, debe ser tomado en consideración como manifestación de voluntad de las partes, como negocio jurídico bilateral que obliga a los que a él se someten, siempre y cuando no vulnere lo dispuesto en el referido artículo 1255 del Código Civil y no sea contrario a los intereses de los hijos menores de edad (...) en cuanto a lo referente a la procedencia o no de la pensión compensatoria concedida en favor de la esposa y a cargo del marido, es de constatar, partiendo de la fuerza vinculante del convenio en todas aquéllas cuestiones relativas al Derecho de familia que no sean de orden público, que la misma efectivamente no procede en el caso que nos ocupa, tal como sostiene el recurrente, pues ningún pago por este concepto acordaron los cónyuges hoy en litigio en el indicado convenio regulador de los efectos de su separación».

14 SAP, Sección 12. a, Barcelona, 17.10.2001 (SP/SENT/33057). 
económicos, sentimentales, de dignidad, etc. Es más, podía estar integrada la renuncia en una transacción judicial de las contempladas en el art. $1.809 \mathrm{CC}$, con objeto de evitar un pleito o poner término al que habían comenzado.

Pero en cuanto al caso concreto de la pensión compensatoria futura, LÓPEZ MARCO ${ }^{15}$ mantiene que, en realidad, lo que esta sentencia niega es la validez de la renuncia de ley, prohibida por la redacción del art. $4 .^{\circ}$ del $\mathrm{CC}^{16}$, que, al dictarse la Sentencia del Tribunal Supremo en que se apoya la Audiencia, estaba vigente y no la renuncia anticipada de derechos. El texto vigente del art. 6. 2. ${ }^{\circ} \mathrm{CC}$ establece que "la exclusión voluntaria de la ley aplicable y la renuncia a los derechos en ella reconocidos sólo serán válidas cuando no contrarien el interés o el orden público ni perjudiquen a terceros». El Tribunal Supremo, en Sentencia de 7 de junio de 1983, considera «la exclusión voluntaria de la Ley aplicable admitida por la preceptiva contenida en el ap. 2 del art. $6 .^{\circ}$ de nuestro Código civil con la restricción de que no contrarie el interés o el orden público, ni perjudique a tercero, ...». Son éstos, pues, los únicos límites a la facultad de renunciar y no otros.

Cita la autora mencionada en apoyo de su interpretación a DÍEZ PICAZO $^{17}$, que entiende que, a tenor del citado art. $6 .^{\circ} .2 \mathrm{CC}$, existen dos formas de renuncia: la renuncia a los derechos que han sido ya adquiridos, y la renuncia a la ley, entendida como voluntad de no llegar a adquirir aquellos derechos que por la normal aplicación de la ley se tendrían o llegarían a tener, y que dentro del concepto de ley aplicable cabe englobar no sólo el bloque de reglamentación de una materia o situación, sino también cada una de las reglas de ese bloque.

No es preciso extendernos en que las prohibiciones a renunciar a los alimentos futuros o al derecho a alimentos no son de aplicación al caso que nos ocupa, ya que la jurisprudencia y la doctrina en su inmensa mayoría consideran que la pensión compensatoria carece de la naturaleza jurídica de los alimentos, hasta el punto de que la senten-

15 LÓPEZ MARCO, Pilar: Renuncia anticipada a la compensación por desequilibrio económico derivado de la separación o divorcio. Comentario a la sentencia 690/2000 de 12 de diciembre de la AP Asturias (S. 5. a)». Pendiente de publicación.

${ }_{16}$ Dicho texto señalaba que «Son nulos los actos ejecutados contra lo dispuesto en la Ley, salvo los casos en que la misma Ley ordene su validez».

17 DIEZ PICAZO, El Sistema de derecho Civil, volumen I. Ed. Tecnos. 4. ${ }^{a}$ edición, Madrid 1981, p. 228. Para este autor la renuncia preventiva ues, en otras palabras, un negarse a adquirir". Rechaza, no obstante, que se trate de una renuncia en sentido técnico, argumentando que «no hay extinción del derecho subjetivo por una disposición de su titular, ya que ese derecho no formaba parte de su patrimonio. Parece, por ello, más apropiado hablar de "exclusión de ley». 
cia del Tribunal Supremo ya mencionada de 2 de diciembre de 1987 reconoció el carácter dispositivo de la pensión compensatoria ${ }^{18}$.

En relación con la indemnización por trabajo de casa (art. 1438 CC), es muy contundente la SAP Murcia, Sec. 1. ${ }^{a}$, de 29 de octubre de $2003^{19}$.

Por otra parte, la SAP Álava, Sec. 1. a, de 25 de abril de $2002^{20}$, determinó la validez de lo pactado al determinar una cantidad en concepto de indemnización del art $1.438 \mathrm{CC}$, que la Sala consideró igualmente eficaz si se asimilaba a una pensión compensatoria. No obstante, la mención en sus razonamientos ${ }^{21}$ de que en este caso no

18 STS, Sección 1. a, 2.12.1987. Pte.: Fernández-Cid de Temes.

19 Sentencia n. ${ }^{\circ}$ 374/2002 (JUR 2003/1008). Recurso de Apelación núm. 422/2002. Pte: Moreno Millán: «Pero es que además concurre un dato esencial y determinante que excluye de manera automática el éxito de la medida compensatoria de referencia. Nos estamos refiriendo al pacto o acuerdo contractual llevado a cabo por ambos cónyuges días antes de la celebración del matrimonio. Nótese que se pacta el régimen de separación de bienes y además se especifica lo siguiente: de un lado que cada una de las partes atenderán por separado las necesidades de sus respectivas familias por cuanto uno y otro son divorciados y han generado en sus precedentes nupcias un concreto núcleo familiar.

Por otra parte y para la atención de ellas y también del núcleo familiar común, el Sr. Arturo se obliga a contratar a su cargo, personal doméstico suficiente con el fin de evitar que su esposa deba atender personal y directamente tales necesidades del hogar, lo que será reintegrado con cargo exclusivo a los bienes propios del citado Sr. Arturo.

Es decir que, ya con anterioridad al matrimonio, ambos cónyuges excluyen, de acuerdo con el contenido del pacto segundo mencionado, la posibilidad de aplicación del controvertido artículo 1.438 del Código Civil. De ahí que la pretensión que ahora ejercita la Sra. Antonia resulte improcedente, máxime porque, como antes decíamos, no existe constancia de esa dedicación de la misma a las tareas domésticas. Es evidente que frente a la realidad y contundencia de tal pacto, no puede prevalecer ahora ni puede resultar contradicho, por los testimonios de determinadas amigas de la solicitante»

Concluye la sentencia reiterando la validez y eficacia de dicho pacto que es, sin duda, una clara y explícita renuncia a la aplicación de la medida compensatoria prevista en el artículo 1.438 del Código Civil. .

${ }^{20}$ Recurso núm.56/2002. (JUR 2003/231109). Pte: Madaria Azcoitia.

21 Esta resolución es del siguiente tenor: "Como antecedente de importancia es de destacar que los esposos contrajeron matrimonio el 26 de diciembre de 1990, otorgando el 30 de diciembre de 1991 capitulaciones matrimoniales, en escritura pública, donde se estableció el régimen de separación de bienes, pactando, entre otras cláusulas, la siguiente: "A la extinción del régimen económico matrimonial pactado en las presentes capitulaciones, en base a lo dispuesto en el art. 1438 del Código Civil, D. Juan Antonio se compromete y asume la obligación de abonar a Dña. Maite la cantidad de treinta millones (30.000.000) de pesetas, si se extingue por causa de fallecimiento, y la cantidad de quince millones (15.000.000) de pesetas, en caso de extinción por causa distinta al fallecimiento. Estas cantidades estarán sujetas a las siguientes revisiones».

«Se plantea por la recurrente y actora una pretensión de reconocimiento del derecho a una pensión compensatoria y, acumuladamente, el cumplimiento del acuerdo 
existen hijos y de que nadie había invocado perjuicio de un cónyuge, para no considerar necesaria la aprobación judicial, parece diluir la claridad de lo fallado.

prestado en capitulaciones, con la subsidiaria de reconocer la pensión compensatoria a cuenta de la referida indemnización acordada en capitulaciones. Pretensiones a las que se opone el demandado. La sentencia de instancia hace una razonable valoración de la prueba en orden a descartar la procedencia de una pensión compensatoria, argumentando entre otros, que la propia ejecución de lo pactado en capitulaciones supone un activo en favor de la esposa revelador de la falta de desequilibrio y empeoramiento de la situación anterior a la separación. Y es en ese punto en el que ahora debemos abundar, pues en su abstracción jurídica tanto la estipulación quinta de las capitulaciones matrimoniales como la pensión compensatoria, participan de la misma naturaleza indemnizatoria y reparadora de un desequilibrio y empeoramiento económico imputable a la separación matrimonial. En el caso de la referida estipulación, se hace además mención expresa del art 1.438 del Código Civil, presumiblemente con ánimo de reparar y recuperar el desequilibrio que el nuevo régimen económico, separación de bienes, iba a causar a la demandante, quien desde las capitulaciones no participaría ya de las ganancias, rentas futuras obtenidas por el esposo, art 1.347 del Código Civil. Por ello acuerdan la compensación citada, que cumple la función propia de la pensión compensatoria, pues ese pago será causa de no darse el supuesto de hecho que justifica la pensión compensatoria o pensión que de la conjunta interpretación de los arts. 97 y 99 del Código Civil, puede deducirse procedente al ser pactada y aceptada por ambos cónyuges. Por tanto, asumida asimismo como límite de la eventual reclamación indemnizatoria de la esposa y configurarse mediante la entrega de un capital que objetivamente y de común acuerdo estima el valor del perjuicio y el importe de la indemnización. Pacto válido y conforme a las reglas de la contratación, admisible en la libertad de pactos, art. 1.255 del Código Civil, sin que tal acuerdo se vea afectado por la referida limitación del art. 90 del Código Civil, pues no existen hijos del matrimonio y no se prueba, ni siquiera alega, que el pacto sea gravemente perjudicial para alguno de los cónyuges. De ahí que deba observarse el principio "pacta sunt servanda", recogido en el art. 1.258 del Código Civil en relación con el art. 1.323 del mismo Cuerpo Legal, previo el referido control específico que debe ejercer el Tribunal en materia de separación matrimonial sobre los pactos a que hubieran llegado los cónyuges, como expresamente impone el citado art. 90 sobre el convenio regulador. Obligación que, indudablemente, queda integrada en los pronunciamientos que en este juicio han de hacerse sobre los efectos económicos de la separación matrimonial, pues causada la separación matrimonial ha de entenderse que si el régimen económico vigente en ese momento era el de separación de bienes también se produce definitivamente el efecto de revocación de consentimientos y poderes, así como el cese de la posibilidad de vinculación de bienes privativos del otro cónyuge en el ejercicio de la potestad doméstica, extinguiéndose, por ello, el régimen pactado. En definitiva, la sentencia firme de separación matrimonial produce, entre otros efectos, la disolución de régimen económico matrimonial, siendo causa de su liquidación, como resulta de los arts. 90 y 95 del Código Civil, y por ello desde su dictado se da el supuesto de hecho previsto en la estipulación quinta de la escritura de capitulaciones matrimoniales de treinta de diciembre de 1.991, siendo exigible, con efectos de esa fecha, su cumplimiento.

De lo actuado en el juicio no consta que el referido pacto indemnizatorio se viera afectado por causa alguna de extinción de la obligación de las contempladas en el art. 1.156 del Código Civil, por lo que, nacida la obligación de pago y cumplida la con- 
Por otra parte, la SAP Granada, Sec. 3. ${ }^{a}, 14$ mayo $2001^{22}$, pese a reconocer la eficacia de los pactos prematrimoniales alcanzados en capitulaciones matrimoniales por los cónyuges y, entre ellos, la renuncia a la pensión compensatoria, considera que el cambio de circunstancias operado en la economía del matrimonio, deja sin efecto la aplicación de lo convenido y concede a la esposa una pensión del art. $97 \mathrm{CC}^{23}$.

dición, ha de entenderse íntegra y exigible conforme a lo pactado. No son reconocibles en concepto de abono de esa indemnización, las cantidades que el demandado pudo entregar a su esposa antes de la presentación de la demanda de separación, pues tales entregas, a falta de otras pruebas no pueden sino reputarse cumplimiento de la obligación natural de alimentos, auxilio y contribución al sostenimiento de las cargas comunes». Por su parte, la SAP, Sección 2. ${ }^{a}$, Almería, 17-2-2003 rechazó la posibilidad de establecer en capitulaciones matrimoniales una pena económica para el esposo en caso de cese de la convivencia conyugal durante el primer año, con una cantidad estipulada anualmente para el caso de cese durante el resto de la convivencia, la Sala por tanto, desestima el recurso - sobre la base de que, si bien el ordenamiento jurídico gira en torno al principio de libertad de pactos, ésta tiene un límite en las buenas costumbres, la ética o la moral, considerando, en definitiva, que dicha cláusula es nula porque limita los derechos que corresponden al cónyuge.

${ }_{22}$ Recurso de Apelación núm. 79/2000. AC 2001/1599. Pte: Albiez Dormán.

23 Los razonamientos son los siguientes: «Primero:.-Es preciso señalar que los cónyuges, antes de contraer matrimonio, suscribieron capitulaciones matrimoniales para establecer que su régimen económico era el de la separación de bienes, pactando, entre otras estipulaciones, que ambos comparecientes convienen que la 'separación o disolución del futuro matrimonio, en ningún caso, llevará como consecuencia la fijación de la pensión compensatoria a que se refiere el artículo 97 del Código Civil, por no producir desequilibrio entre los cónyuges». Esta cláusula contenida en las capitulaciones matrimoniales es claramente atípica, atendiendo a lo que entiende por capitulaciones matrimoniales el artículo 1.325 del CC. Pero es válida, puesto que la pensión por desequilibrio es un derecho disponible, según ha podido declarar el TS en su importante sentencia de 2 de diciembre de 1987 (RJ 1987/9174) y, por tanto, es perfectamente renunciable. Así lo acordaron mutuamente los futuros contrayentes cuando firmaron la escritura pública en fecha de 27 de diciembre de 1991. Con la celebración del matrimonio el 7 de enero de 1.992, los pactos capitulares adquirieron plena eficacia de acuerdo con lo dispuesto en el artículo 1.334 del CC, y, por ello, también la cláusula de renuncia recíproca a una futura pensión por desequilibrio económico. Se puede calificar como un pacto con vistas a una futura separación (el TS no rechaza, en principio, los acuerdos de separación no homologados por una resolución judicial - SS. 22 abril 1997 (RJ 1997. 3251), 19 diciembre 1997 (RJ 1997. 9110) y 21 diciembre 1998 (RJ 1998, 9649). En el momento en que se redactó la cláusula, los futuros cónyuges tenían sus propios ingresos al estar ejerciendo cada uno su profesión.

Aun cuando este pacto vincula a ambos cónyuges, cuando la esposa presenta la demanda de separación solicita, no obstante, la pensión compensatoria, porque las circunstancias son, a su juicio, ahora muy distintas a las que sirvieron de base para pactar aquella cláusula. Es un hecho cierto, y además expresamente reconocido, que el marido trabaja para una empresa de laboratorios farmacéuticos como representante, por cuyo trabajo se veía obligado a desplazarse fuera de la capital, acompa- 
Lo que perturba en la renuncia de este derecho futuro es tanto la base de su existencia -desequilibrio y comparación en las personas y en tiempo: la situación del otro cónyuge y anterior en el matrimonio- como las de su cuantía, no sólo cabe que se hayan modificado de forma extrema desde que se suscribió el pacto renunciatorio -incluso previo a la unión-, sino que además estos cambios hubieran sido impensables en el momento de la firma. ¿Cabría aplicar el principio de rebus sic stantibus?

La STS Sala 1. a, de 22 de octubre de $1999^{24}$ expresa que «no se comparte que no sea posible renunciar a una expectativa de derecho, por cuanto es perfectamente posible que ante cualquier situación de futuro que incrementase el patrimonio de una persona pueda ésta, de antemano, dentro de su libertad contractual negociar sobre ese incremento». La STS Sala 1. a de 5 de abril de $1997^{25}$ dice que «(...) aparte de que cabe renunciar a un derecho eventual futuro y que su renuncia fue clara, explicita, inequivoca, terminante y sin dudas sobre su significado (...) no hay contrato, ni negocio jurídico bilateral, sino unilateral, con voluntad abdicativa de un derecho, $o$, si se quiere, expectativa tutelada por la Ley». La SAP Madrid, de 22 de junio de $2002^{26}$, conviene en que «la renuncia de los derechos reconocidos por la ley admitida con carácter general por el art. 6.2 del Código Civil ('la exclusión voluntaria de la ley aplicable y la renuncia a los derechos en ella reconocidos sólo serán válidas cuando no contrarien el interés o el orden público o perjudiquen a terceros') siempre que no contraríe el interés o el orden público ni perjudique a terceros puede ser descrito en general, como la declaración jurídica de voluntad por la cual un sujeto separa de su propia esfera jurídica un Derecho subjetivo, expectativa, facultad, pretensión, beneficio, seguridad, garantía o posición jurídica, distinguiéndose las especies de renuncia abdicativa, preventiva o recognoscitiva según que

ñándole su esposa. También es un hecho constatado, igualmente no negado por el marido, que la esposa, antes de casarse, trabajaba, dejando su trabajo al momento de casarse. Desde entonces, la esposa no ha realizado actividad profesional alguna, siguiendo a su marido en los distintos destinos laborales. Esta circunstancia ya es suficiente por sí sola para entender que las bases para la suscripción de aquel pacto han dejado de existir, pudiendo, por tanto, pedir la pensión compensatoria si se dan las circunstancias previstas en el art. 97 del CC. Se puede traer aquí a colación la teoría de la base objetiva del negocio jurídico, tímidamente admitida en algunas resoluciones del TS (SS. 30 junio 1948 [RJ 1948. 1115], 30 de diciembre 1985 [RJ 1985,6620] y 20 de abril 1994 [RJ 1994,3216]), que puede tener lugar cuando la base o la causa que se tuvo en cuenta en el acuerdo negocial desaparece al no tener ya ningún sentido su mantenimiento».

24 Pte: Martínez Calcerrada Gómez.

25 Pte; Fernández-Cid de Temes.

26 EDJ 2002/47900. 
venga referida respectivamente a un derecho adquirido, diferido o simplemente dudoso o controvertido".

En principio debe primar la libertad contractual, siempre que no existan cuestiones afectadas por la ley o el orden público, que no concurren en este supuesto. La disponibilidad clara de la pensión compensatoria debe comprender la posibilidad de renuncia preventiva. La única condición que debe contemplarse es la de eficacia del consentimiento que en esta materia, como en tantas otras, debe contener una exigencia especial de que ese consentimiento sea debidamente informado. En una materia como la que nos ocupa, la información de los ciudadanos es escasa y con frecuencia completamente equivocada. Con reiteración contemplamos como convenios reguladores y documentos semejantes se otorgan con un solo abogado, lo cual es una práctica absolutamente nociva. Habitualmente ese sólo abogado es en realidad de una de las partes con lo cual la otra está indefensa. Para renunciar a derechos es necesario que el renunciante conozca cual es el contenido de ese derecho y cuáles las consecuencias de esta renuncia.

\section{RENUNCIA TACITA}

Se plantea también la eficacia de la renuncia tácita, reconocida en general por el Tribunal Supremo, entre otras en Sentencia de 24 de julio de 1989, sobre la que no existe doctrina pacífica. Se considera como tal, el no ejercicio del derecho a reclamar la fijación de la pensión. La sentencia del Tribunal Supremo de 2 de diciembre de 1987, repetidamente citada, ha señalado que:

"... es claro que no nos encontramos ante una norma de derecho imperativo, sino ante otra de derecho dispositivo, que puede ser renunciada por las partes, no haciéndola valer».

La jurisprudencia menor ha contemplado distintos supuestos en que ha considerado la renuncia tácita, por no reclamar la pensión oportunamente. Así se ha estimado, por ejemplo, cuando nunca le pidió el acreedor después de la cesación de la convivencia, e incluso no lo hizo en la demanda de separación ${ }^{27}$; o señalando que precluye el derecho a pedirla si no se hizo 17 años después en la separación ${ }^{28}$.

27 AP, Sección1. a, Sta. Cruz de Tenerife 9 de octubre de 1990; AP, Sección 3. a , Granada 10 de diciembre de 1998 (Pte.: Mascaró Lazcano) (La Ley, 1999, 5402).

28 AP, Sección 2. ${ }^{a}$, Cáceres 28 de febrero de 1997 (ACAud. núm. 13, 1-15 de julio de 1997,p. 1457). 
También, se ha juzgado que debe pedirse al romperse la convivencia ${ }^{29}$ y que la no inclusión en el convenio de la separación constituye una renuncia ${ }^{30}$.

ROCA TRÍAS ${ }^{31}$ no se muestra favorable a la consideración de renuncia tácita a la ausencia de pacto sobre la pensión en el convenio regulador ${ }^{32}$. No será suficiente - dice- el silencio del acreedor, sino que debería deducirse muy claramente la voluntad del afectado. La realidad - continúa - es que estando sujeta a prescripción, mientras no transcurra el término de ella, podrá pedirse la pensión. Existen diferentes resoluciones judiciales que exigen algo más para que el silencio se valore como renuncia tácita, como que de las circunstancias se deduzca tal renuncia, sin que la simple ausencia del pacto sea suficiente para deducirla ${ }^{33}$.

En la Ley de Enjuiciamiento Civil 1/2000, de 7 de enero, las pretensiones que tengan por objeto materias sobre las que las partes puedan disponer libremente, constituyen excepciones de las normas generales de indisponibilidad del objeto del proceso en los de capacidad, filiación, matrimonio y menores y podrán ser objeto de renuncia, allanamiento, transacción o desistimiento (artículo 751.3 de la LEC 2000). Es de aplicación la doctrina del Tribunal Supremo, ya citada, en cuanto a la disponibilidad de cuanto esté incluido en el aspecto puramente económico afectante a los cónyuges ${ }^{34}$.

${ }^{29}$ AP, Sección 18. ${ }^{\text {a }}$, Barcelona 8 de enero de 1999 (Pte.: Noblejas Negrillo) (RJC II, 99, p. 344).

30 AP, Sección 21. a, León 15 de enero de 1997 (Pte.: Álvarez Rodríguez) (ACAud. núm. 23, 11-15 de diciembre de 1997).

31 ROCA TRÍAS, Encarna: Comentarios al Código Civil y Compilaciones Forales, tomo II, artículos 42 al 107 CC dirigidos por Manuel Albaladejo, Ed. Revista de Derecho Privado/Edersa, 2. ${ }^{a}$ ed., Madrid 1982, p. 644.

32 En este mismo sentido, la sentencia AP Ávila, 4 de abril de 1994 (ACAud. núm. $19,1 / 15$ de octubre de 1994, p. 2172) y AT Cáceres 2 de noviembre de 1988 ( $R G D$ 1989, p. 6149).

${ }_{33}$ AP, Sección 1. ${ }^{\text {, }}$ Murcia 24 de septiembre de 1996 (ACAud. núm. 12/16, 30 de junio de 1997, p. 1381); AP, Sección 1. ${ }^{\text {a }}$, Pontevedra 11 de noviembre de 1997 (Pte.: Pérez-Batallón Ordóñez) (La Ley, 1998, 2329).

34 Es posible el allanamiento, pero hay que subrayar que la rebeldía no debe confundirse con aquél. Tal y como señala la AP, Sección $1 .^{a}$, Vizcaya 14 de octubre de 1993 (ACAud. núm. 2, 16/31 de enero de 1994). "... el estado de rebeldía de la demandada no puede considerarse en nuestra legislación como un allanamiento a la pretensión del actor ni como un reconocimiento de los fundamentos de hecho de la demanda. Entendida la rebeldia como oposición a la demanda, al demandante le corresponde acreditar los hechos constitutivos de su pretensión y sobre la causa alegada para la extinción del derecho a la pensión compensatoria..” 


\section{RENUNCIA A FAVOR DE TERCEROS}

Dentro del concepto de disposición del derecho a la pensión se plantea la posibilidad de hacerlo en favor de terceros. Para HAZA DÍAZ ${ }^{35}$ el acreedor puede ceder su crédito o sus acreedores pueden subrogarse en su derecho, (...) cuando los actos concretos a través de los cuales se manifiesta el poder de disposición (transmisión, cesión, donación, etc.) no lesionen gravemente el interés de ninguno de los ex cónyuges y esa falta de perjuicio esté verificada por el juez.

ROCA TRIAS ${ }^{36}$ distingue entre la transmisibilidad del crédito que, por su carácter personalísimo considera improcedente y la de la deuda amparada en la posibilidad contemplada por el artículo 101.2. . $\mathrm{CC}$ en favor de los herederos en caso de fallecimiento del deudor.

La condición de personalísimo del derecho a la pensión la excluye de la norma general del artículo $1.112 \mathrm{CC}$.

La propia HAZA DÍAZ ${ }^{37}$, partiendo de que es el componente alimenticio el que puede limitar la transmisibilidad del crédito, manifiesta que:

«... resulta más coherente y, sobre todo, aplicable a la pensión concretamente, partir del propio límite que impone la Ley, en cuya virtud la cantidad de dinero o de bienes en que se fija la prestación que sobrepase lo necesario para la subsistencia, está dentro del ámbito de disponibilidad de las partes, puesto que su transmisión, cesión y demás actividades en que se manifiesta no implican lesión grave para el acreedor o el deudor de la pensión.»

En todo caso, parece admisible que el deudor pueda disponer de su crédito con consentimiento del acreedor. Si el acreedor puede renunciar a la pensión, que es lo más, evidentemente puede legítimamente realizar lo menos, que es la sustitución del deudor.

35 HAZA DÍAZ, Pilar: La pensión de separación y divorcio, La Ley, Madrid 1989, p. 78

${ }^{36}$ ROCA TRÍAS, Encarna: Comentarios al Código Civil y Compilaciones Forales, tomo II, artículos 42 al 107 CC. Dirigidos por Manuel Albaladejo. Ed. Revista de Derecho Privado/Edersa, 2.a ed., Madrid 1982, p. 621.

37 HAZA DÍAZ, Pilar: La pensión de separación y divorcio, La Ley, Madrid 1989. p. 78 . 


\section{CONCLUSION}

Por lo que se refiere a los pactos de renuncia a la pensión compensatoria realizados antes de la ruptura conyugal, se mantiene por quienes defienden la postura de admitir la exclusión, que ambos contrayentes quedan en situación de igualdad porque ambos pierden el derecho a la pensión. Sin embargo, habrá que estudiar caso por caso tal renuncia ya que si con la pensión del art. 97 pretende el Legislador compensar la disparidad económica que la ruptura del matrimonio crea en las condiciones de vida de los esposos, atendiendo a las necesidades de uno y a los recursos del otro en el momento de la crisis, el pacto previo de exclusión de la ley, en determinados casos, puede que, no solo no respete la igualdad, sino que, más bien, la conculca. Ya que es precisamente la consideración a la diferente situación de ambos, a sus diferentes circunstancias, la que justifica el trato desigual de uno respecto del otro y la fijación de la pensión. Es la igualdad como diferenciación, que supone la existencia de diferencias relevantes, la que justifica ese trato desigual; y son las circunstancias relevantes (como la edad), las circunstancias personales (la vejez, la condición del conyuge desfavorecido), y las situaciones de hecho desiguales en determinadas relaciones jurídicas (usuarios, consumidores, arrendatarios, asegurados, trabajadores), las que justifican un trato diferenciado para restablecer así el equilibrio conforme a la idea de Justicia.

Por lo que se refiere a los pactos realizados con posterioridad a la ruptura conyugal, las partes pueden en virtud de renuncia negocial en el Convenio Regulador, no fijar pensión de desequilibrio, y en un momento posterior, declararla extinguida, siempre, claro esta, que se respeten los limites fijados por la ley y los derechos de terceros, sobre todo los derechos de los hijos.

\section{BIBLIOGRAFIA}

De castro y Bravo, F. "Las condiciones generales de los contratos y la eficacia de las leyes". Ed. Civitas, Madrid 1.987.

Peces-Barba, G. «Curso de Teoría del Derecho». Ed. M. Pons, Madrid 2.000. Perez Luño, A. «Teoría del Derecho».Ed. Tecnos, Madrid 1.997.

BarCeló DoméNech, Javier: «La extinción del derecho a la pensión por el cese de la causa que la motivo». AC 1999-3.

MARIN GARCIA DE LEONARDO, Maria Teresa: «Los acuerdos de los cónyuges en

la pensión por separación y divorcio», Tirant lo Blanch. Valencia, 1995. 